\title{
Populasi Lychas mucronatus (Scorpiones:Buthidae) di Kampus Undip Tembalang Semarang.
}

\author{
Arief Fatkhu Rohman, Mochamad Hadi, Udi Tarwotjo \\ Laboratorium Ekologi dan Biosistematik Jurusan Biologi FMIPA Undip
}

\begin{abstract}
Scorpion is an animal that has a high adaptability in various environmental conditions. Lychas mucronatus is one species of scorpion of the Buthidae family, which can be found on Campus Diponegoro University, Semarang Tembalang. No data population and the spread of L. mucronatus on the campus of Diponegoro University, Semarang Tembalang. This study aims to assess the population of L. mucronatus on the campus of Diponegoro University, Semarang Tembalang. This research was conducted in October-November 2009 in the region Undip Tembalang Hyderabad campus. Samples were taken by hand collecting techniques directly in the field accompanied by an image capture scorpion on its habitat. L. population data mucronatus were analyzed descriptively. The results showed L. mucronatus found on campus Undip Tembalang were 22 specimens consisting of 15 females, 2 males, 1 juvenile, and 4 specimens of unknown gender. L. mucronatus females in this study more likely in because of male mortality during mating season. L. mucronatus was found in grassland and shrub habitats, fields, and around the tree, L. mucronatus occupy four types of microhabitat characteristics, namely: leaf litter, rotten wood, in the soil, and under stones. L. mucronatus most common in grassland and shrub habitats with sloping contour with microhabitat under a rock. The presence of predators and competitors are likely to be a factor not found in L. mucronatus in several locations on campus Undip Tembalang.
\end{abstract}

Key words: population, scorpions, Buthidae, Lychas mucronatus, microhabitat

\begin{abstract}
Abstrak
Kalajengking adalah binatang yang memiliki kemampuan adaptasi tinggi di berbagai kondisi lingkungan. Lychas mucronatus merupakan salah satu spesies kalajengking dari famili Buthidae, yang dapat ditemui di Kampus Undip Tembalang Semarang. Belum ada data populasi dan persebaran L. mucronatus di kampus Undip Tembalang Semarang. Penelitian ini bertujuan untuk mengkaji populasi L. mucronatus di kampus Undip Tembalang Semarang. Penelitian ini dilakukan pada bulan Oktober-November 2009 di kawasan kampus Undip Tembalang Semarang. Pengambilan sampel dilakukan dengan teknik hand collecting secara langsung di lapangan disertai pengambilan foto kalajengking pada habitatnya. Data populasi L. mucronatus dianalisis secara deskriptif. Hasil penelitian menunjukkan L. mucronatus yang ditemukan di kampus Undip Tembalang sebanyak 22 spesimen terdiri atas 15 betina, 2 jantan, 1 juvenil, dan 4 spesimen tidak diketahui jenis kelaminnya. L. mucronatus betina yang lebih banyak dalam penelitian ini kemungkinan di karenakan mortalitas jantan selama musim kawin. L. mucronatus ditemukan pada habitat padang rumput dan semak, tegalan, dan di sekitar pohon, L. mucronatus menempati empat tipe karakteristik mikrohabitat, yaitu : serasah daun, kayu lapuk, di dalam tanah, dan di bawah batu. L. mucronatus paling banyak ditemui pada habitat padang rumput dan semak dengan kontur miring dengan mikrohabitat di bawah batu. Keberadaan predator dan kompetitor kemungkinan menjadi faktor tidak ditemukannya $L$. mucronatus pada beberapa lokasi di kampus Undip Tembalang.
\end{abstract}

Kata kunci : populasi, kalajengking, Buthidae, Lychas mucronatus, mikrohabitat

\section{PENDAHULUAN}

Kampus Undip Tembalang terletak di daerah perbukitan. Kondisi alami yang masih terdapat disekitar kampus Undip ini menjadikannya habitat berbagai jenis hewan diantaranya seperti burung, serangga, dan juga kalajengking.
Salah satu jenis kalajengking dari famili Buthidae yang dapat ditemui di kampus Undip Tembalang adalah Lychas mucronatus. $L$. mucronatus memiliki warna dasar kuning kecokelatan dengan pola kehitaman pada tubuh, kaki, segmen terakhir metasoma (Vacon dan Abe, 
1988). Jantan dibedakan dari betina pada jari pedipalp proximal melengkung (Gambar 1), jadi tepinya tidak dapat bertemu (Kovarik, 1997) .Di Indonesia L. mucronatus dapat dijumpai di Jawa, Flores, Lombok (Kovarik, 1997).

Belum banyak penelitian mengenai populasi kalajengking dan sebagian besar data yang tersedia merupakan kalajengking spesies dari Amerika dan Eropa, seperti Centruroides margaritatus (Polis, 1990b), Mesobuthus gibbosus (Kaltas et al, 2006), Centruroides vittatus (Yamashita, 2004), untuk itu perlu dilakukan pengkajian populasi $L$. mucronatus guna mengetahui keberadaannya di kampus Undip Tembalang Semarang.

Permasalahan yang muncul adalah bagaimana populasi L. mucronatus (Scorpiones : Buthidae) di kampus Undip Tembalang Semarang. Tujuan penelitian ini adalah untuk mengkaji populasi L. mucronatus (Scorpiones : Buthidae) di kampus Undip Tembalang Semarang. Penelitian ini diharapkan dapat memberikan informasi mengenai populasi L. mucronatus (Scorpiones : Buthidae) di kampus Undip Tembalang Semarang sebagai upaya untuk perlindungan, pelestarian, dan pemanfaatannya secara berkelanjutan.

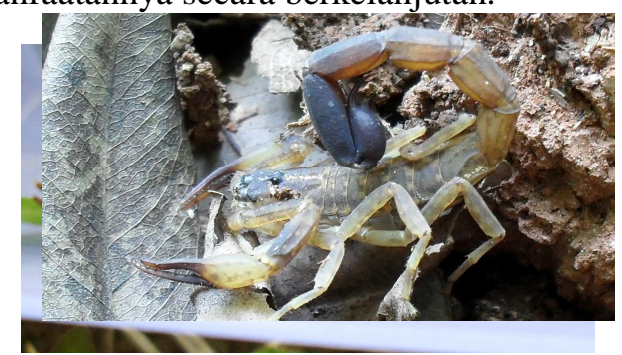

Gambar 1. L. mucronatus betina (A), L. mucronatus jantan (B)

\section{BAHAN DAN METODE}

\section{A. Alat dan Bahan}

Alat yang digunakan pada penelitian ini antara lain : selotip, kamera digital, toples plastik, pinset, tang kecil, tongkat kayu/besi, gunting, termometer tanah, termohigrometer, soil tester. Bahan yang digunakan dalam penelitian ini adalah : L. mucronatus di lingkungan kampus Undip Tembalang.

\section{B. Metode Penelitian}

Penelitian dilakukan dengan pencarian kalajengking pada pagi hingga siang hari, yaitu mulai pukul 9.00 hingga pukul 12.00 di kawasan kampus Undip Tembalang pada periode OktoberNovember 2009 dengan lokasi sebagai berikut: FMIPA, Rektorat, UPT Perpustakaan, Widya Puraya, Institut Obat Bahan Alami, Jurusan Sejarah, Planologi, Teknik Sipil, Poliklinik, Masjid Kampus, Peternakan, Dekanat Fakultas Teknik, Teknik Elektro, Teknik Mesin, Perikanan, D III.

Kalajengking dicari dengan mengangkat batu, tumpukan kayu, serasah, membongkar kayu lapuk, dan menggali gundukan tanah. Kalajengking ditangkap menggunakan pinset atau tang kecil pada bagian metasoma, untuk selanjutnya dimasukkan ke dalam toples plastik. Selotip digunakan untuk memudahkan pengambilan gambar bagian coxaternal region. Foto kalajengking diambil di habitat alami, didalam toples plastik (untuk mendapatkan gambaran morfologi pada saat identifikasi), lokasi penemuan.

Data fisik lingkungan yang diambil adalah kelembaban dan temperatur udara menggunakan termohigrometer, temperatur tanah menggunakan termometer tanah, dan $\mathrm{pH}$ tanah menggunakan soil tester. Analisis data untuk populasi $L$. mucronatus dilakukan secara deskriptif.

\section{HASIL DAN PEMBAHASAN}

\section{A. Populasi L. mucronatus}

Berdasarkan hasil penelitian selama bulan Oktober-November 2009 di kampus Undip Tembalang terdapat beberapa lokasi penemuan $L$. mucronatus yaitu Rektorat bagian utara, kampus Sejarah bagian timur dan barat, kampus D III di sebelah utara (Tabel 1 ).Total spesimen $L$. mucronatus yang ditemukan adalah 22 spesimen, masing-masing terdiri atas 15 betina, 2 jantan, 1 juvenil, dan 4 spesimen yang tidak diketahui jenis kelaminnya (tidak berhasil ditangkap)

Sebagian besar L. mucronatus yang ditemukan pada penelitian ini adalah betina sebanyak 15 spesimen, ditemukan di Rektorat bagian utara, kampus Sejarah bagian timur dan barat, kampus D III di sebelah utara. Sedangkan pada penelitian ini 2 spesimen jantan hanya ditemukan di Rektorat bagian utara. Warburg \& Polis (1990) menyatakan aktifitas musiman dari kalajengking jantan berbeda dengan kalajengking 
betina, sebagian besar spesies kalajengking di Amerika Utara, betina lebih aktif di musim semi (hingga Juni) dan di musim gugur (setelah September), sedangkan jantan lebih aktif selama pertengahan musim panas. Penemuan $L$. mucronatus betina selama bulan OktoberNovember 2009 menunjukkan adanya kesamaan pola aktifitas musiman dengan kalajengking di Amerika Utara.

Sedikitnya penemuan L. mucronatus jantan dalam penelitian ini kemungkinan berkaitan dengan ditemukannya beberapa betina yang mungkin dalam keadaan bunting (bagian mesosomanya lebih besar dibandingkan betina yang lain). Penemuan ini menunjukkan bahwa telah terjadi musim kawin sebelum penelitian, kalajengking jantan (yang telah mencapai kedewasaan) mengalami peningkataan mobilitas selama musim kawin (untuk mencari betina) sehingga rentan terhadap predator, disamping itu seringkali terjadi kanibalisme dilakukan betina terhadap jantan. Predini (2006) menyatakan tingkat kematian umumnya tinggi pada kalajengking jantan karena peningkatan mobilitas selama musim kawin dan kanibalisme oleh betina.

Tabel 1. Data L. mucronatus yang ditemukan pada lokasi pencarian di kampus Undip Tembalang.

\begin{tabular}{|c|c|c|c|}
\hline Lokasi & Spesies & Jumlah Spesimen & Keterangan \\
\hline FMIPA & - & 0 & Tidak ditemukan \\
\hline Rektorat & $\begin{array}{l}\text { Famili Buthidae, } \\
\text { L. mucronatus }\end{array}$ & 6 & $\begin{array}{l}2 \text { spesimen ditemukan di } \\
\text { bawah batu, } \\
3 \text { spesimen di bawah } \\
\text { serasah daun, dan } \\
1 \text { spesimen di dalam kayu } \\
\text { lapuk sisa rumah rayap, } \\
\text { Lokasi Rektorat Utara }\end{array}$ \\
\hline UPT Perpustakaan & - & 0 & Tidak ditemukan \\
\hline Widya Puraya & - & 0 & Tidak ditemukan \\
\hline Institut Obat Bahan Alami & - & 0 & Tidak ditemukan \\
\hline Jurusan Sejarah & $\begin{array}{l}\text { Famili Buthidae, } \\
\text { L. mucronatus }\end{array}$ & 10 & $\begin{array}{l}8 \text { spesimen ditemukan di } \\
\text { bawah batu, dan } \\
2 \text { spesimen di dalam } \\
\text { gundukan tanah } \\
\text { Lokasi sebelah barat dan } \\
\text { timur Kampus sejarah }\end{array}$ \\
\hline Lokasi & Spesies & Jumlah Spesimen & Keterangan \\
\hline Planologi & - & 0 & Tidak ditemukan \\
\hline Teknik Sipil & 一 & 0 & Tidak ditemukan \\
\hline Poliklinik & - & 0 & Tidak ditemukan \\
\hline Masjid Kampus & - & 0 & Tidak ditemukan \\
\hline Peternakan & - & $\begin{array}{l}0 \\
0\end{array}$ & $\begin{array}{l}\text { Tidak ditemukan } \\
\text { Tidak ditemukan }\end{array}$ \\
\hline $\begin{array}{l}\text { Dekanat Fakultas Teknik } \\
\text { Teknik Elektro } \\
\text { Teknik Mesin }\end{array}$ & - & $\begin{array}{l}0 \\
0\end{array}$ & $\begin{array}{l}\text { Tidak ditemukan } \\
\text { Tidak ditemukan }\end{array}$ \\
\hline
\end{tabular}


Perikanan

D III

\begin{abstract}
$-$
Famili Buthidae,

L. mucronatus
\end{abstract}

0

6
Tidak ditemukan

5 spesimen ditemukan di bawah batu dan 1spesimen di dalam tanah. Lokasi di sebelah utara kampus D III
Tiga spesimen L. mucronatus betina dewasa ditemukan mengelompok di sebelah utara kampus DIII, dua betina dewasa L. mucronatus ditemukan di sebelah barat kampus Sejarah. Spesimen $L$. mucronatus yang berkumpul merupakan spesimen betina dewasa, Kovarik (2006) menyatakan $L$. mucronatus dapat hidup dalam kelompok dan fenomena ini juga terdapat pada spesies Lychas lainya, sebagaimana dikemukakan Polis (1990b) bahwa kalajengking dari famili Buthidae lainnya juga berkumpul dalam kelompok dari 5 sampai 25 ekor sebagai contoh di sebelah selatan Australia kelompok L. marmoreus sejumlah 10 sampai 17 ekor berkumpul di bawah kulit kayu Eucalyptus.

\section{B. Mikrohabitat}

Berdasarkan lokasi penemuan $L$. mucronatus, dapat dikelompokkan menjadi empat karakteristik mikrohabitat (Tabel 2), yaitu serasah daun, kayu lapuk, di dalam tanah, dan di bawah batu. Polis (1990b) menyatakan kalajengking tidak ditemukan secara acak di dalam habitat, namun kalajengking umumnya ditemukan dalam spesifik mikrohabitat.

Penemuan L. mucronatus pada mikrohabitat serasah daun di Rektorat karena pada lokasi ini dikelilingi pohon-pohon yang menyediakan keberadaan serasah daun. L. mucronatus bersembunyi di bawah serasah daun untuk bersembunyi dari terik sinar matahari, sebagai kamuflase, disamping itu juga di balik serasah daun dapat ditemukan berbagai jenis invertebrata yang dapat menjadi mangsa potensial bagi $L$. mucronatus. Kalajengking dapat menggunakan mikrohabitat untuk makan, mencari mangsa atau sebagai tempat berlindung (McReynolds, 2008).

L. mucronatus yang ditemukan di dalam kayu lapuk hanya seekor dan ditemukan di Rektorat dekat garasi bus Undip. Di dalam kayu lapuk tempat penemuan L. mucronatus juga ditemui 4 sisa eksoskeleton lama yang berukuran kecil, diduga merupakan strategi bagi $L$. mucronatus yang hendak melakukan molting untuk menghindari pemangsaan, dilihat dari ukuran sisa eksoskeleton yang kecil mungkin tempat tersebut digunakan juvenil untuk menghindari pemangsaan maupun kanibalisme kalajengking dewasa. Kalajengking muda menggunakan mikrohabitat yang berbeda dengan kalajengking dewasa sebagai tempat perlindungan (Polis, 1980).

Tabel 2. Penemuan L. mucronatus di berbagai mikrohabitat

\begin{tabular}{cccccc}
\hline & & \multicolumn{4}{c}{ Jumlah spesimen pada tiap mikrohabitat } \\
\cline { 3 - 6 } Lokasi & $\begin{array}{c}\text { Jumlah total } \\
\text { spesimen }\end{array}$ & $\begin{array}{l}\text { Serasah } \\
\text { daun }\end{array}$ & Kayu lapuk & Di dalam tanah & Di bawah batu \\
\hline Rektorat & 6 & 3 & 1 & 0 & 2 \\
Sejarah & 10 & 0 & 0 & 2 & 8
\end{tabular}




\begin{tabular}{llllll} 
D III & 6 & 0 & 0 & 1 & 5 \\
\hline Total & 22 & 3 & 1 & 3 & 15 \\
\hline
\end{tabular}

L. mucronatus yang terdapat pada mikrohabitat di dalam tanah ditemukan di sekitar gedung kampus Sejarah di bagian barat dan timur juga di sebelah utara gedung kampus D III. Sebagian besar L. mucronatus ditemukan di tanah dengan kontur miring, kadang pada tanah yang terpotong dengan kemiringan kurang lebih $90^{\circ}$. Tanah memiliki karakteristik remah, terlihat seperti gundukan kecil, beberapa gundukan tanah terdapat pada pohon pisang yang sudah mati mungkin sisa rumah rayap. Faktor fisik yang mempengaruhi penemuan kalajengking diataranya adalah karakteristik batu atau tanah dan batuan atau serasah penutup permukaan tanah (Polis, 1990b).

L. mucronatus kemungkinan memanfaatkan tanah relatif lembut dan mudah remah untuk menyusup ke dalam tanah, atau menggali tanah tersebut dan mengubur tubuh mereka dengan tanah, sehingga gundukan terbentuk. Lychas mucronatus kadang memanfaatkan celah-celah tanah dan liang serangga (misalnya semut) lain untuk masuk ke dalam tanah. Kalajengking kadang ditemukan di dekat sarang semut dan rayap (McReynolds, 2004).

Dilihat dari ukuran tubuh L. mucronatus yang ditemukan di di dalam tanah adalah juvenil atau kalajengking muda, ini merupakan strategi untuk menghidari pemangsaan maupun kanibalisme kalajengking dewasa. Aktifitas musiman kalajengking dewasa disesuaikan dengan kelimpahan mangsa, sedangkan aktifitas kalajengking muda cenderung menghindari kalajengking dewasa dan kompetisi makanan (Warburg \& Polis, 1990).

Penemuan sisa eksoskeleton di dalam gundukan tanah, adalah strategi $L$. mucronatus ketika melakukan molting. Polis dan Sissom (1990) menyatakan sebelum molting, kalajengking menjadi lebih tersembunyi dan tidak aktif, beberapa spesies menjadi tidak aktif selama 24 jam sebelum kutikula baru terbentuk. Kondisi tidak aktif ini membuat kalajengking menjadi rentan terhadap pemangsaan, oleh karena itu $L$. mucronatus bersembunyi di dalam tanah saat molting untuk menghindari pemangsaan.

L. mucronatus yang terdapat pada mikrohabitat di bawah batu ditemukan di Rektorat, kampus Sejarah, maupun di kampus D III (Tabel 2). Di lokasi kampus Sejarah dan D III $L$. mucronatus paling sering ditemui di bawah batu pada lokasi dengan kontur miring, Margules et al (1994) menyatakan bahwa ada kemungkinan penemuan kalajengking pada lereng lebih besar dibandingkan di tanah datar. Bentuk bagian dasar batu sering kali relatif datar, batu tidak tertanam dengan dalam di tanah, L. mucronatus juga ditemukan pada tumpukan bebatuan.

Druce (2000) menyatakan penemuan kalajengking di suatu tempat dipengaruhi oleh $\mathrm{pH}$ tanah, temperatur udara, dan ketebalan serasah daun. Perbandingan faktor fisik lingkungan antar lokasi pencarian dapat dilihat pada (Tabel 3) dan (Gambar 2) Faktor fisik lingkungan belum dapat menunjukkan bukti yang dapat menjelaskan keberadaan L. mucronatus pada masing-masing mikrohabitat. Penemuan L. mucronatus pada mikrohabitat yang berbeda kemungkinan adalah bentuk tingkah laku untuk menghindari kompetisi antar spesies dan kanibalisme.

Tidak ditemukannya L. mucronatus di sebelah utara Rektorat, sebelah timur dan barat kampus Sejarah, dan sebelah utara kampus D III terlihat tidak dipengaruhi oleh faktor fisik lingkungan, namun kemungkinan dikarenakan adanya keberadaan predator dan kompetitor kalajengking, karena di lokasi dimana $L$. mucronatus tidak ditemukan, sering dijumpai Arachida lain yaitu ordo Uropygi, Amblypygi, Araneae, dan class Cilopoda, yang merupakan pemangsa inverterbrata kecil, termasuk serangga. Penemuan beberapa Cilopoda yang berukuran besar, memungkinkan Cilopoda tersebut tidak hanya berperan sebagai kompetitor, namun juga berpotensi sebagai predator. 
Tabel 3. Data fisik lingkungan pada lokasi pencarian L. mucronatus di kampus Undip Tembalang.

\begin{tabular}{lcccc}
\hline \multicolumn{1}{c}{ Lokasi } & $\begin{array}{c}\text { Temperatur } \\
\text { Udara }\left({ }^{\circ} \mathrm{C}\right)\end{array}$ & $\begin{array}{c}\text { Kelembaban } \\
\text { Udara }(\%)\end{array}$ & $\begin{array}{c}\text { Temperatur } \\
\text { Tanah }\left({ }^{\circ} \mathrm{C}\right)\end{array}$ & pH Tanah \\
\hline FMIPA & 28.33 & 71.00 & 28.33 & 6.75 \\
Rektorat & 29.00 & 60.33 & 29.33 & 6.75 \\
UPT Perpustakaan & 27.33 & 71.00 & 27.67 & 6.58 \\
Widya Puraya & 27.33 & 60.33 & 29.33 & 6.83 \\
Institut Obat Bahan & & & & \\
Alami & 26.33 & 59.67 & 29.33 & 6.83 \\
Sejarah & 30.67 & 54.67 & 29.33 & 6.17 \\
Planologi & 29.33 & 56.33 & 29.67 & 5.08 \\
Teknik Sipil & 30.33 & 54.00 & 30.33 & 6.67 \\
Poliklinik & 29.67 & 64.00 & 30.00 & 6.50 \\
Masjid Kampus & 33.33 & 45.67 & 30.33 & 6.17 \\
Peternakan & 32.33 & 48.33 & 33.33 & 6.83 \\
Dekanat Fakultas & & & & \\
Teknik & 28.33 & 68.00 & 28.67 & 4.92 \\
Teknik Elektro & 29.67 & 59.67 & 30.67 & 5.92 \\
Teknik Mesin & 30.00 & 64.67 & 31.00 & 6.67 \\
Perikanan & 29.00 & 66.00 & 29.33 & 6.83 \\
D III & 31.67 & 54.33 & 32.33 & 7.00 \\
\hline
\end{tabular}

Keterangan : $\quad$ warna biru, hijau dan merah menunjukkan masing-masing lokasi penemuan L. mucronatus.

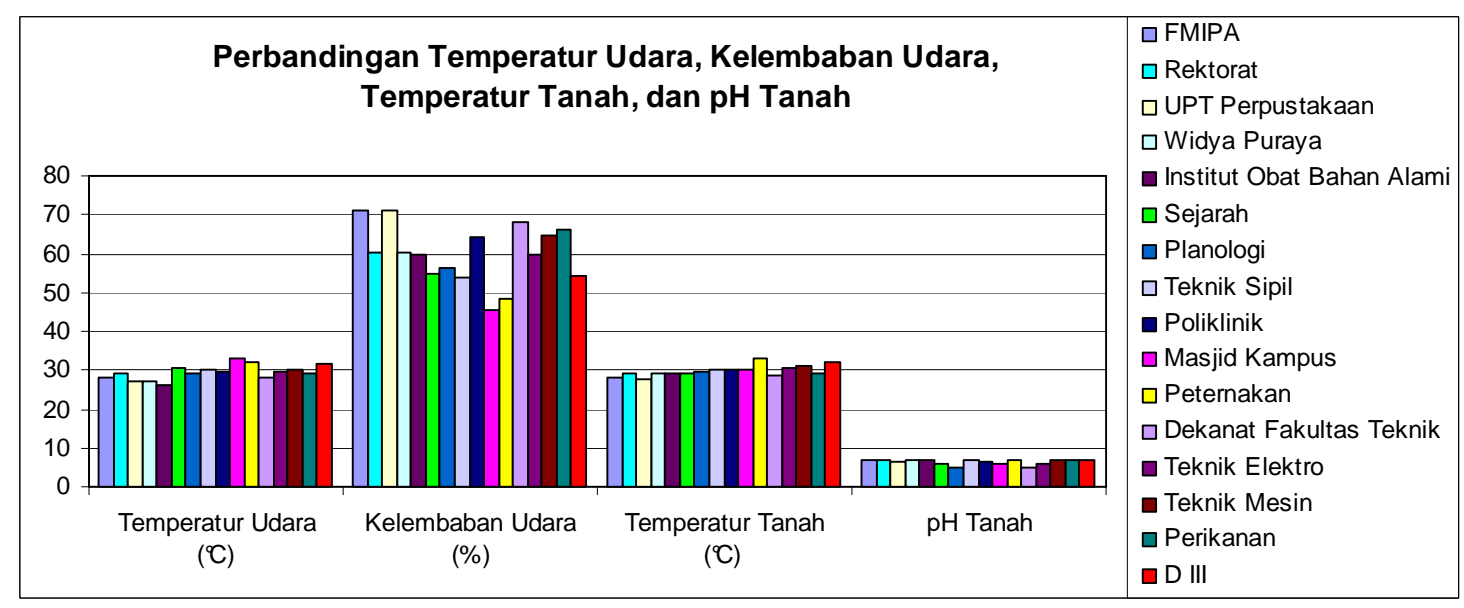

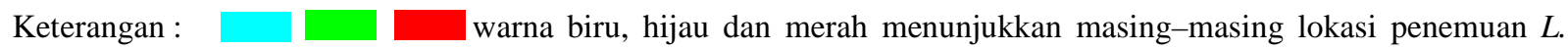
mucronatus.

Gambar 2. Grafik perbandingan data fisik lingkungan pada lokasi pencarian L. mucronatus. 


\section{KESIMPULAN}

Kesimpulan yang dapat diambil dari penelitian ini, adalah $L$. mucronatus yang ditemukan di kampus Undip Tembalang sebanyak 22 spesimen terdiri atas 15 betina, 2 jantan, 1 juvenil, dan 4 spesimen tidak diketahui jenis kelaminnya. L. mucronatus betina ditemukan lebih banyak dalam penelitian ini kemungkinan dikarenakan mortalitas jantan selama musim kawin. L. mucronatus ditemukan pada habitat padang rumput dan semak, tegalan, dan di sekitar pohon. L. mucronatus menempati empat tipe karakteristik mikrohabitat, yaitu: serasah daun, kayu lapuk, di dalam tanah, dan di bawah batu. $L$. mucronatus paling banyak ditemui pada habitat padang rumput dan semak dengan kontur miring dengan mikrohabitat di bawah batu. Keberadaan predator dan kompetitor kemungkinan menjadi faktor tidak ditemukannya $L$. mucronatus pada beberapa lokasi di kampus Undip Tembalang.

\section{UCAPAN TERIMA KASIH}

Ucapan terima kasih kami berikan kepada Fredian Bentar Kumolo, Agum Daru .S, Danni Kristiyanto, Danang Bayu Andika, M. Khusni Hidayat dan M. Sigit Santoso atas bantuan yang telah diberikan.

\section{DAFTAR PUSTAKA}

Druce, D. J. 2000. Factors affecting millipede, centipede and scorpion diversity in a savanna environment. Thesis. School of Life and Environmental Sciences University of Natal, Durban.

Kaltas, D., Stathi, I. and Mylonas, M. 2006. The effect of insularity on the seasonal population structure of Mesobuthus gibbosus (Scorpiones: Buthidae). Euscorpius 44: 1-6.

Kovarik, F. 1997. Revision of the genera Lychas and Hemilychas, with descriptions of six new species (Scorpiones: Buthidae). Acta Societatis Zoologicae Bohemoslovenicae 61: 311-371.
2006. Breeding of the scorpion Lychas mucronatus. Akva tera forum. 2(1): 58-59.

Margules, C.R., Milkovits, G.A. \& Smith, G.T. 1994. Contrasting effects of habitat fragmentation on the scorpion Cerophonius squama and an amphipod. Ecology 75:20332042.

McReynold, C. N. 2004. Temporal patterns in microhabitat use for the scorpion Centruroides vittatus (Scorpiones: Buthidae). Euscorpius 17: 35-34.

2008. Microhabitat preferences for the errant scorpion, Centruroides vittatus (Scorpiones, Buthidae). The Journal of Arachnology 36:557-564.

Polis, G. A.1990a. Introduction. In : Polis, G.A (Ed.). Biology of Scorpions. Standford University Press, California. .1990b. Ecology. In : Polis, G.A (Ed.). Biology of Scorpions. Standford University Press, California.

.1980. The Effect of Cannibalism on the Demography and Activity of a Natural Population of Desert Scorpions. Behavioral Ecology and Sociobiology 7: 25-35.

Polis, G. A and Sissom W. D.1990. Life History. In : Polis, G.A (Ed.). Biology of Scorpions. Standford University Press, California.

Predini,

$$
\text { L. } 2006 .
$$

Scorpiones.http://www.accessscience.com. 4 Agustus 2008.

Vachon, M and Abe, T. 1988. Colonization of Krakatau islands (Indonesia) by Scorpion. Acta Arachnol 37 : 23-32.

Warburg, M. R \& Polis, G. A.1990. Behavioral Responses, Rhythms, and Activity Patterns. In : Polis, G.A. Biology of Scorpions. Standford University Press, California.

Yamashita, T. 2004. Surface activity, biomass, and phenology of the striped scorpion, Centruroides vittatus (Buthidae) in Arkansas, USA. Euscorpius 17: 25-32. 